\title{
Perception of multilevel factors for entrepreneurial innovation success: A survey of university students
}

\author{
BALÁZS BORSI ${ }^{1^{*}}$ (1) and TIBOR DÖRY ${ }^{2}$ (1) \\ ${ }^{1}$ Eszterházy Károly University, Eszterházy tér 1, H-3300, Eger, Hungary \\ ${ }^{2}$ Széchenyi István University, Győr, Hungary
}

Received: November 23, 2018 • Revised manuscript received: February 27, 2019 • Accepted: April 6, 2019

(c) 2020 The Author(s)

\begin{abstract}
Entrepreneurial innovation is a complex phenomenon. Experimenting with research designs that could claim some degree of generalizable linking between the individual and external influencing factors is challenging. However, progress even in research niches can contribute to a more structured understanding of the process. This article focuses on the first stages of entrepreneurial innovation, using a novel questionnaire design. Responses were collected from two Hungarian universities (147 and 127 responses, respectively) and analysed using Structural Equation Modelling. The results confirm that entrepreneurial innovation success in the early stage is shaped by macro-level factors, which have an influence on risk perception through locus of control. The paper makes two contributions, demonstrating (1) the possibility of using questionnaire survey for analysing multiple levels if the narrative is under control, and (2) how individual entrepreneurs approach the start of their innovation-based business, upon which personality and environmental factors both have significant impact.
\end{abstract}

\section{KEYWORDS}

multilevel analysis, entrepreneurial innovation, story-based questionnaire, entrepreneurial narrative

\section{JEL CLASSIFICATION INDICES}

031

*Corresponding author. E-mail: borsi.balazs@uni-eszterhazy.hu 


\section{INTRODUCTION}

Innovation is a highly uncertain, complex and multilevel phenomenon involving individual, organisational, cultural and various systemic contexts. Considering the multiple contexts during micro-level measurement, delineation of the causes and effects during the process of innovation are methodologically challenging. There are only a few attempts at the individual level of enquiry, which, at the same time, take into consideration the multiple contexts and their potential impacts on innovation (Meyer - Goes 1988; Hueske et al. 2015 are two examples).

Three main aspects of the innovation process are emphasised in the innovation literature (Fagerberg 2005). First, the fundamental uncertainty of projects; the second is the speed to move quickly before somebody else does; and third, the resistance to new ways at all levels of society. These aspects explain why one does not know in advance whether an innovation will make its way in the real world. There are many uncertainties (Jalonen 2012), which make the decisionmaking like 'driving in the fog' (Tidd - Bessant 2013).

The process, through which innovation occurs, usually starts with an idea/invention, and innovation is the first attempt to carry it out in practice (Fagerberg 2005). Although the two are closely linked, they are not easily distinguished and there might be a significant time lag, sometimes even decades, between the two phenomena. In a general framework of the innovation process, first there is a 'matchmaking', involving the exploration and exploitation of opportunities for new or improved products, processes and services, and then there is a learning process, which is highly uncertain and it is not at all easy to predict the cost and market for the new artefact (Pavitt 2005). Inventions or ideas can originate from all kinds of entities and individuals, still, the innovator plays a key role, which differs from that of the inventor (or idea 'originator'): an innovator combines the factors necessary for implementing the ideas/inventions. Schumpeter (1934) called this person an entrepreneur and defined one form of innovation as new combinations of existing resources.

There are various knowledge dynamics and interactions involved during the processes of innovation, each of which has its own management challenge. The 'ideation' phase (Vandenbosch et al. 2006) and the 'fuzzy front end' of new venture formation are still rarely researched, for which one of the main reasons is the challenge of obtaining relevant data (Woolley 2011). The early stages are usually chaotic and unorganised. There is a fuzzy zone between the time when an innovation opportunity is recognised and the time when serious efforts are carried out (Gassman - Schweitzer 2012).

From a manageability stance, innovation can be regarded as a process of gradually reducing the related uncertainties. The further one goes in the 'innovation funnel' the more resources it will require and the more it will cost, but also more becomes known about the uncertainties. The innovation funnel is a roadmap that provides support to make decisions about resource commitment (Dunphy et al. 1996; Tidd - Bessant 2013). On the road there are gates with clear decision points at the end of each preceding stage. Having stepwise decisions along the process instead of making one big commitment at the much riskier outset is more reasonable for entrepreneurs. $^{1}$

\footnotetext{
${ }^{1}$ The basic 'stage-gate' model was developed by Cooper (1994), who studied several thousands of new product development projects. There are many variations of the original model. Tidd - Bessant (2013) for instance differentiate i) the concept outline, ii) detailed design, iii) testing and iv) launch phases of innovation processes.
} 
In this paper article we focus on entrepreneurial innovation. In the economy there are many different innovation processes taking place. One of these is the introduction of new products and new services to the market done by an entrepreneur through a new venture, in which case an entrepreneurial innovation is implemented. In the early stage the exploitation of emerging new business opportunities corresponds to the innovation funnel concept and the first two phases preliminary investigation and building the business case - of the stage-gate model (Cooper 1994). Our aim is to empirically connect some theoretical considerations that have emerged during the entrepreneurship research and the first stages. First, we overview the theoretical background in search for factors that were found to have an influence on the new venture formation and the fuzzy front end. We do this in order to devise a simple theoretical model that can be used for measuring individual factors and higher-level constructs that have an impact upon innovation. An accorded 'multilevel' research design is expected to contribute to a more structured and more precisely measured understanding of the entrepreneurial innovation process. We introduce a questionnairebased research design to test with methodological and structural hypotheses the measurability of the theoretical model and we present the research results, which also point to the analytical potential of the approach applied. Conclusions are drawn at the end of the paper.

\section{THEORETICAL APPROACH}

'Innovation is the specific tool of entrepreneurs, the means by which they exploit change as an opportunity for a different business or a different service' (Drucker 1985: 19). ${ }^{2}$ Innovation is therefore present in the thinking about entrepreneurs.

Innovative ideas can come from different sources and situations such as inspirations, transferring an idea in a different context ('creativity'), observing and understanding of customer needs, from public research, discoveries, as well as combinations of existing knowledge into something new. There are different ways and alternative models to explore options, depending on the choice of the innovator. The mode of exploitation often depends on some trigger signal that offers an interesting variation of the opportunity to the innovator. Successful entrepreneurs can select the key opportunities out of thousands of possibilities (Bessant - Tidd 2011) and exploit those. On the road of exploitation, personal, sociological, organisational and environmental factors exert their influence and an innovative idea may develop into a viable enterprise (Bygrave - Zacharakis 2011).

For analysing the ideation phase and the first stages of entrepreneurial innovation the entrepreneurship, opportunity research and innovation literatures offer different approaches.

The personality-trait approach emphasizes the personal characteristics of entrepreneurs, who are assumed to have certain personality features that enhance entrepreneurial activity (Farhangmehr et al. 2016). Internal locus of control, i.e. an individual's belief about his ability to control events, is one of the most studied personality traits (Mueller - Thomas 2001). Recent endeavours aim at mapping the entirety of intraindividual dynamics, and locus of control is also in a central position (Obschonka - Stuetzer 2017). When the opportunity is evaluated (Shepherd et al. 2007) entrepreneurial action will be taken in the light of perceptions, or, as the mental

${ }^{2}$ Entrepreneurial innovation may also involve processes and practices of opportunity creation, which is out of the scope in this article. 
model theory states, 'as people process information, they create cognitive images to represent reality and make predictions' (Wood et al. 2014: 253). The cognitive theories of entrepreneurship deal with how individuals process and judge external signals (Robinson - Marino 2015). Additionally, individuals differ in terms of coping with the risks of the entrepreneurial process. Risk propensity will determine how risk is evaluated in general (a longer-term personality trait) and risk perception will refer to the labelling of certain situations, the probability estimation of outcomes, and the confidence in doing and managing so, whereby opportunities and threats are also analysed (Zhang et al. 2015).

In the study of entrepreneurship, the most widely applied general behavioural model is the theory of planned behaviour (TPB, Ajzen 1991). The theory connects personality traits and perceptions, and entrepreneurial intentions are explained with personal attitudes, social pressure and perceived difficulties (see for example, Krueger et al. 2000; Gird et al. 2008; Kautonen et al. 2013). TPB assumes that actual behaviour can be predicted by intentions of the individual together with his or her resources under control. To examine entrepreneurial intentions, it focuses on three predominant determinants: attitude, social norm and the perceived behavioural control. The first, attitude, addresses the degree to which an individual has a favourable or unfavourable evaluation of the components of the behaviour in question. The second, social norm, concerns the perceived social pressure to perform or not perform the behaviour. The last determinant is about resources and opportunities that are necessary to carry out the behaviour. The behavioural approach to entrepreneurship studies lays stress on the learning process, whereby entrepreneurs respond to the environment, and a person even with all the entrepreneurship traits might not become an entrepreneur (Farhangmehr et al. 2016).

The opportunity-focused literature is a relatively new direction in entrepreneurship research. Attempting to clarify the opportunity concept itself, Davidsson (2015) argues that an appropriate scientific study should equally pay attention to external enablers (macro-level circumstances), new venture ideas (imagined future ventures) and opportunity confidence (perceived favourability), as knowledge about the person alone cannot explain entrepreneurial action and outcomes.

Inspired by innovation research and recognizing the need for a systemic approach, Ács et al. 2015) introduced the concept of National Systems of Entrepreneurship (NSE). Such systems are driven by individuals, but the NSE theory highlights that apart from complex and systemic interactions, the individual-level entrepreneurial action is regulated by contextual factors, including culture, formal institutions and resource availability. Context is also a recent focus of entrepreneurial innovation studies. Early context-centric research emphasised the role of institutional structures, multilevel approaches argued if entrepreneurial opportunities are 'found' or 'made' by entrepreneurs whose efforts are moderated by contexts, whereas more recent constitutive approaches view entrepreneurial innovation as a process wherein actors and contexts are co-created, and narratives play a key role (Garud et al. 2014).

Overall, despite the scholarly progress made about how individual (or micro) level factors are linked to external (or macro) factors, the picture is far from being thoroughly elaborate. We propose to experiment with measurement that first takes some core considerations of the literature on board. What are these? When the entrepreneurial innovation processes start at the fuzzy front end, individuals perceive risks and external environmental signals, based upon which decisions are made 'internally'. Yet there are different possible response outcomes, depending on the contexts and narratives, which also have an impact on the perceptions. In entrepreneurship research this challenge is exemplified by the Individual-Institutional-Opportunity Nexus 
(Fortunato - Alter 2011). All of the constituents depend on one another, so it becomes a methodological necessity to control as many of them as possible in any empirical measurement attempt. ${ }^{3}$ In our research approach, opportunity will be taken as fixed through a case-based narrative, which is expected to assist in delineating the impact of individual and external or environmental factors on entrepreneurial decisions. If the narrative perspective of a concrete innovation case can be taken for 'granted' or 'fixed', an entrepreneurial innovation depending on personality traits, will be perceived by a person as a favourable or unfavourable opportunity, wherein institutions will also have their impact (Fig. 1).

Fixing the narrative implies advantages for building a testable model if any of the discussed theoretical approaches - which involve uncertainty, perceptions and risks - is taken. The main advantage is that the individual and external factors can better be controlled. Additionally, the narrative of the story brings in a so-called 'transportation experience', the feeling of being transported into and taking part in the narrative world (Glaser et al. 2012), which enables better quality responses for all questions directly related to the story, as the innovation will much better be remembered throughout the measurement.

\section{RESEARCH AND MEASUREMENT DESIGN}

To study the early stage of entrepreneurial innovation, a questionnaire survey was designed with the involvement of university students. In terms of cognitive differences between individuals, university students offer a more homogenous population than, for instance, representative sampling of the population. Although they are not measured directly, important factors of the TPB (such as social pressures, social norms and available resources) are also more homogenous among university students. A university is a melting pot of smart and ambitious young people with wide-ranging disciplinary backgrounds, who can easily interact (Houser 2014), so entrepreneurship discussions are more likely to happen, making the measurement concepts easier to deliver to them. Entrepreneurial intentions decrease with age (Hatak et al. 2015), so smaller student samples are expected to deliver more robust results than other representations of the population.

Despite the advantages discussed, surprisingly few research projects used case-based narratives in entrepreneurial innovation research and few used questionnaire design involving (higher education) students. ${ }^{4}$ The non-individual specific factors of entrepreneurial innovation rarely appear in the research designs and the perception-based psychological approaches seem also lacking. Parental self-employment is the most frequent 'hard' external variable (Bergmann et al. 2016; Camacho-Minano - del Campo 2017). Socio-economic background factors

\footnotetext{
${ }^{3}$ Zhang et al. (2015) also confirm that 'the inconsistency in the empirical results [in entrepreneurship research] indicates a necessity to model all determinants [of the theory of planned behaviour] in different contextual settings.'

${ }^{4}$ A Web of Science search (downloading meta-data: 20 October 2017) had the following results. A total of 46 articles included the terms 'entrepreneur' and 'innovation' and 'student' and 'survey' in their topic description. Having read the abstracts, 8 articles were not innovation focused, 13 articles did not survey students. 2 articles were in Spanish. The methods in 2 articles did not rely on a questionnaire survey. One article had a non-random sampling of only 29 students. One article focused on a competition programme. One article had a narrow psychological science focus. The remaining 18 articles were carefully read if at least the personal level cause and effect relationships have been studied with a sufficiently detailed theoretical model. Buli - Yesuf (2015) applied a clear TPB approach. 4 relevant articles remained; these are cited in the main text.
} 


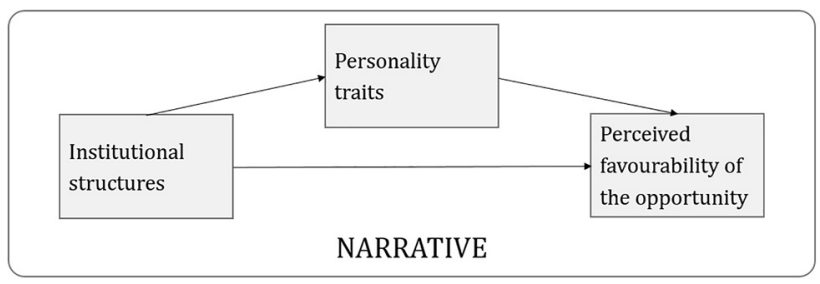

Fig. 1. Generalised relationships of individual and environmental factors at the start of entrepreneurial innovation (with a fixed narrative)

(individualism, family tradition and education) were linked to personality traits (risk-taking propensity, innovativeness, tolerance of ambiguity and locus of control) in Gurel et al. (2010). Bergmann et al. (2016) have delivered complex measurement providing some of the needed interdisciplinary and multilevel bridging, but perception of non-individual specific factors has been ignored in the questionnaire design. Perceptions are offered only in Kuckertz - Wagner (2010), who attempted to measure the relationship between sustainability orientation and entrepreneurial intentions, taking into account perceived support factors for and perceived barriers to becoming self-employed (and the effect of these factors proved to be either controversial or not significant).

Within the Hungarian context S. Gubik et al. (2018) applied the theory of planned behaviour to explain entrepreneurial intention of higher education students based on a questionnaire survey. The methodology involves the impact of the context as a smaller portion of the actual behaviour construct and the focus is broader than entrepreneurial innovation.

Overall, there are many articles dealing with entrepreneurial innovation, but only a few with questionnaire design involving (higher education) students. Further, there was no empirical research found with an innovation case-based narrative perspective. Certainly, conventional questionnaire surveys are comfortable as they are supposed to be context-free, universal and convenient to analyse using statistical tools. However, 'the richness of human events and thought cannot be expressed in definitions, statements of fact, or abstract propositions' (Shkedi 2004). So, a narrative method seems appropriate to study the complex innovation phenomenon, but the analytical potential of a quantitative questionnaire is attractive as well.

To fix the narrative, we need a good story to base our survey upon. In a similar vein, Wood et al. (2014: 253) argue that “...for entrepreneurial action to occur, interpretations of opportunity circumstances must be approached from a first-person perspective and hence action is underpinned by the belief that there is an attractive opportunity available for me". Additionally, as gender is an emerging yet often neglected issue in innovation studies (Alsos et al. 2016), if we want to get rid of the bias it may cause, the innovation in the survey should be gender neutral. So, we needed a case-based narrative that is biased towards neither men nor women. We decided to develop the story of a pet washing kit (Box 1$).^{5}$

\footnotetext{
${ }^{5}$ The case was developed as an original gender-neutral idea with international measurement and comparison potential in 2017. In April 2018, however, the authors discovered a somewhat similar existing kit developed by a Hungarian entrepreneur.
} 


\section{Box 1. The pet washing kit story - part 1.}

Suppose that you have had a dog or a cat for a longer time and in the past 1 year you started to experiment with a new bathing kit, which can also be used by elderly or disabled people, who may have problems to wash their pets. To build the prototype had cost you HUF 255000, but you are convinced that it could be manufactured and sold at a price of HUF 165000. The idea is a good one, no special materials are needed, but one part of the kit is original and you think it could easily be an important business secret. In your experience, the average service price for washing an average sized dog or cat is in the range of HUF 1700-2100, and you are confident that if, as an alternative, you start selling the kit, you would make a decent profit. Many people in your neighbourhood have already assured you that they would buy this product for the unit price foreseen (HUF 165000). You are about to implement the idea and grow your business.

Note: HUF 255000 is slightly less than one month of annual gross national income, HUF 165000 is approximately one-twentieth of the annual gross national income (World Bank Data for 2015).

In order to maximise the transportation experience, responders should be deeply involved in the case. Entrepreneurs cannot achieve anything without the involvement of others (Zachary Mischra 2011), so a friend was also invited to the story (Box 2).

Involvement of the respondents was planned to be secured by measuring two latent constructs: 'confidence and honesty of the situation' in Box 1 and 'appropriate informedness of the friend' in Box 2, i.e. the degree to which the friend was chosen to be appropriate in that situation. These latent constructs were measured on a Likert-scale from -3 to +3 , indicating the degree of agreement. Confidence and honesty of the situation was measured by the following statements: 'If my friend asked about confidential business details, I would not tell', 'To that friend I could not tell all details, but only some things that are important for my decisions, 'One should better be careful about telling all details in such situations'. Appropriate informedness of the friend was measured by the following statements: 'My friend is generally doing well in real life problems', 'My friend would be able to understand all the significant details of my problem', 'My friend would easily understand all the important basics of what I want to do'.

The introduction of the pet washing kit case and inviting a close friend to the story were expected to deliver the necessary transportation experience and ensure the measurement of the

\section{Box 1. The pet washing kit story - part 1.}

You decide to discuss your plans with a close friend of yours - whom you think would be the most appropriate person to discuss your idea and the option to start the business, for the first time, on a confidential basis. Please, think of an existing person, WHO IS NOT YOUR RELATIVE, and give the below listed general properties of that friend:

- gender

- age

- educational background / profession (the domain where he/she works or studies currently) 


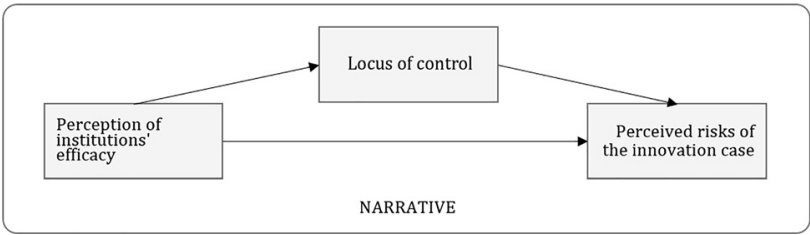

Fig. 2. Model of measuring perception-centred entrepreneurial innovation with a fixed narrative

conceptual model in Fig. 2. The main disadvantage of the method is also related to transportation experience: if the respondent does not feel engaged in the story, the answers collected will be at best tangential to the story.

The model depicted in Fig. 2 is derived from Fig. 1: it takes into account the locus of control (from the traits school), risk perception (the inherent characteristic of entrepreneurial innovation in terms of opportunity evaluation), and higher level of abstractions (such as institutions from the contextual perspective) at the same time. There are several entrepreneurial personality traits studied, such as profiles of the Big Five traits (extroversion, conscientiousness, openness, agreeableness and neuroticism), or the specific traits of risk taking, locus of control and self-efficacy. There are even arguments to define an entire 'Entrepreneurial Personality System' (EPS), interlinked with culture and the sociology of everyday life (Obschonka - Stuetzer 2017). Locus of control and risk-taking are central to the EPS concept. ${ }^{6}$

Perceived institutional efficacy was measured on a Likert-scale from -3 to +3 , the number indicating the degree of agreement with the following statements: 'In case of dispute over e.g. IP, I would trust the authorities to find justice', 'My firm could negotiate with any party because law and the contracts would protect my knowledge and my idea without any problem', 'The legal system in Hungary guarantees the protection of business ideas'. By using these items, the empirics for 'institutions', which is contained in the contextual and constitutive approaches (Garud et al. 2014), opportunity research (Davidsson et al. 2015), NSE theory (Acs et al. 2015), Individual-Institutional-Opportunity Nexus (Fortunato - Alter 2011), were ensured.

The locus of control is measured by using Rotter's measurement design (scale from 0 to 13 , higher values: external, lower values: internal locus of control). Approaching from the concept of psychological well-being, Zhang et al. (2015) used self-determination, a very similar construct to locus of control.

For measuring risk perception of the case, we started from Simon et al. (2000). Their work is one of the notable few exceptions using a case-based questionnaire in entrepreneurship research. A slightly modified set of statements was used (measured on a Likert-scale from -3 to +3 , the number indicating the degree of agreement): 'I would know the main business development directions and would not get lost with making the pet washing kit a real product on the market, I

\footnotetext{
${ }^{6}$ Along with self-efficacy: the measurement of this construct is argued to be strongly related to the locus of control (Judge 2002), so to keep the questionnaire concise, it was decided not to be measured separately.
} 
would not perceive substantial risk of realisation', 'Even if the steps taken that far are logical, I am not confident enough what the next steps would be' [reversed scale], 'Making the pet washing kit business a reality is risky, most probably I would not be able to realise substantial market success' [reversed scale].

Using the conceptual model and the above defined constructs, first the transportation experience as well as all other latent constructs will be tested using Confirmatory Factor Analysis (CFA), then the following hypotheses will be examined as part of a structural equation model that corresponds to the model in Fig. 2:

H1. Locus of control is influenced by the perceived efficacy of institutions.

H2. Locus of control and perceived efficacy of institutions influence the risk perception of the specific innovation case.

CFA can be used to test if the latent constructs were measured reliable in accordance with the researcher's intentions. Structural Equation Modelling (SEM) is a way of finding causal relationships: means, variances and covariances of variables are explained by a smaller set of parameters and the related structure.

The use of SEM is justifiable both on theoretical and methodological grounds. First, individual responders provide answers about their personality traits (locus of control variables), risk perception (perceived risks variables) and the general efficacy of institutions (variables measuring the perceptions about institutional efficacy). Second, the variables are organised into a formal structure, making use of the fixed narrative, as set out above and presented in Fig. 2.

\section{RESULTS}

Using paper-based questionnaires in classrooms, responses were collected from undergraduate students in two Hungarian universities: 147 responses at Széchenyi István University (Győr) and 127 responses at Eszterházy Károly University (Eger).

Most of the respondents from the Széchenyi University was male, doing their engineering studies. The respondents from the Eszterházy University had a more diverse disciplinary orientation and the slight majority was female. $95 \%$ of the respondents belong to the 18-24year-old age group (Table 1).

In both cases, the responding students were instructed to provide answers freely, as there was no good or bad answer. A total of 270 responses was retained for further analysis. ${ }^{7}$

In accordance with the measurement intentions, the narrative of the pet washing kit proved to be gender neutral. $68 \%$ of the respondents indicated that the kit could have been created by either a man or a woman (17\% thought that the kit was created by rather a man, and $15 \%$ thought that it was more likely to have been created by a woman).

\subsection{Transportation experience of the pet washing kit narrative}

Transportation experience, the feeling of being transported into and taking part in the narrative world (Glaser et al. 2012) was measured using six items: three for confidence and honesty of the

\footnotetext{
${ }^{7}$ Four records were omitted because the responses were not reliable (same values were indicated throughout the questionnaire). Probably these four respondents did not want to engage in the story.
} 
Table 1. Students in the sample by university, gender and type of residence

\begin{tabular}{|l|c|c|c|c|c|c|c|}
\hline \multirow{2}{*}{ Residence } & \multicolumn{3}{|c|}{ Eszterházy University } & \multicolumn{3}{c|}{ Széchenyi University } & \multirow{2}{*}{ Total } \\
\cline { 2 - 7 } & Male & Female & n.a. & Male & Female & n.a. & 14 \\
\hline Capital & 3 & 2 & 1 & 7 & 1 & - & 14 \\
\hline Larger city & 13 & 11 & - & 31 & 7 & 2 & 64 \\
\hline Small city & 11 & 27 & 2 & 53 & 11 & - & 104 \\
\hline Village/rural & 18 & 38 & 1 & 28 & 7 & - & 92 \\
\hline Total & 45 & 78 & 4 & 119 & 26 & 2 & 274 \\
\hline
\end{tabular}

Table 2. Measured items (observed variables) for two latent constructs of the transportation experience

\begin{tabular}{|l|l|c|}
\hline Abbreviation & \multicolumn{1}{|c|}{ Item/description } & Mean \\
\hline Confidence and honesty of the situation (latent construct) & -0.277 \\
\hline confhon1 & $\begin{array}{l}\text { If my friend asked about confidential business details, I } \\
\text { would not tell* }\end{array}$ & -0.581 \\
\hline confhon2 & $\begin{array}{l}\text { To that friend I could not tell all details, but only some } \\
\text { things that are important for my decisions }\end{array}$ & -0.442 \\
\hline confhon3 & $\begin{array}{l}\text { One should better be careful about telling all details in } \\
\text { such situations [reversed scale] }\end{array}$ & 1.912 \\
\hline Appropriate informedness of the friend (latent construct) & 1.949 \\
\hline informed1 & My friend is generally doing well in real life problems \\
\hline informed2 & $\begin{array}{l}\text { My friend would be able to understand all the significant } \\
\text { details of my problem }\end{array}$ & 1.915 \\
\hline informed3 & $\begin{array}{l}\text { My friend would easily understand all the important } \\
\text { basics of what I want to do }\end{array}$ & \\
\hline
\end{tabular}

Note: *For all items: Likert scale from -3 to +3 ; the degree of agreement with the statement.

situation construct and three for appropriate informedness of the friend construct (the friend was involved immediately in the pet washing kit narrative; see Box 2 above). The Cronbachalphas were acceptable for both constructs ( 0.74 and 0.65 , respectively), indicating the reliability of measuring (Table 2).

A CFA moderately confirms the measurement of the transportation experience components, between which the expected (negative) sign of the effect was computed (Fig. 3). ${ }^{8}$ Comparative Fit Index $=0.97$; root mean square error of approximation $=0.072$; chi-square $=19.12 ; P$-value (chi-square $)=0.01$; degrees of freedom $=8$, Coefficient of determination $=0.92$.

${ }^{8}$ Figures show the CFA and SEM results in a common format. Single arrows: standardised regression coefficients, double arrows: correlation, boxes bottom right: constants, above circles: variance of the error term. 


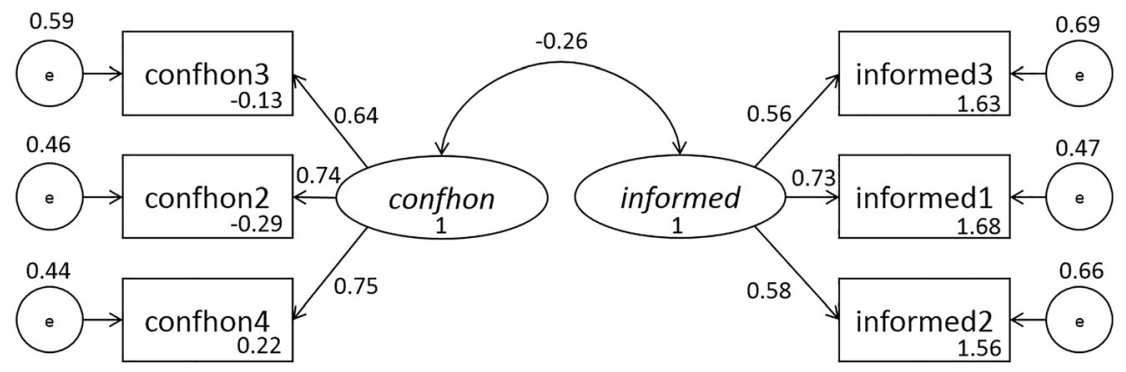

Fig. 3. CFA results for the transportation experience (standardised estimates)

\subsection{The structural model and its modification}

The SEM equations consist of a measurement and a structural component. The former refers to the goodness of measuring the latent constructs and the latter to the structural relationships. Fig. 4 presents the measurement and structural model corresponding to the model in Fig. 2. Tables 3 and 4 below summarise the descriptive statistics. The Cronbach-alphas were weakly acceptable for the perceived institutional efficacy (inst) and risk perception (riskperc) constructs ( 0.55 and 0.58 , respectively), indicating somewhat weak reliability of measuring, but still in the more reliable range.

Fit indices for the structural model (Model 1 in Table 5 below) are good. All estimated parameters are significant $(P<0.05)$ with the exception of the unmediated effect of perceived institutional efficacy on risk perception and the effect of locus of control on risk perception also slightly falls short of the $P<0.05$ threshold. As the effect size of perceived institutional efficacy (on risk perception) was rather small, we re-run the model without this direct effect (Model 2 in Table 5 below) even though modification indices did not indicate the statistical benefits of doing so. Theoretically it remains somewhat less clear if perceived institutional efficacy shall not have some effect on the risk perception of a particular innovation case at all, however, the fit indices improved, and all estimates are now significant. We continue the discussion of parameters using Model 2.

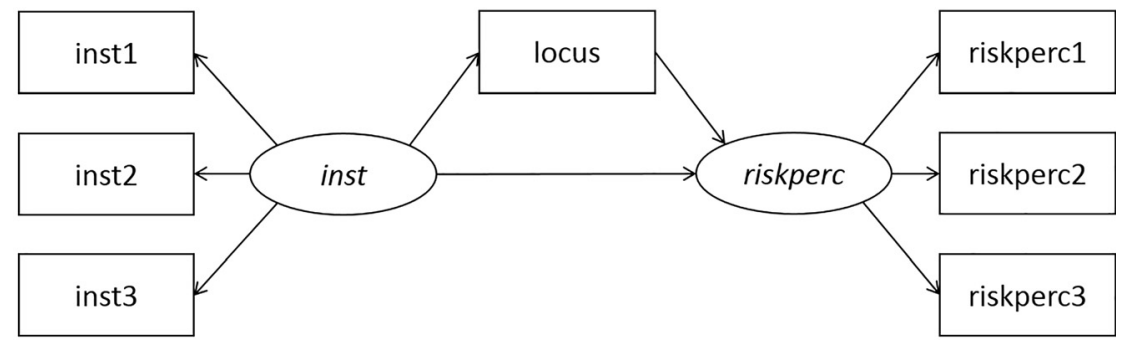

Fig. 4. Structural model with two latent variables (inst = 'perceived institutional efficacy' and 'riskperc $=$ risk perception of the pet washing kit case') 
Table 3. Measured items (observed variables) for the structural and measurement model

\begin{tabular}{|l|l|c|}
\hline Abbreviation & \multicolumn{1}{|c|}{ Item/description } & Mean \\
\hline inst1 & $\begin{array}{l}\text { In case of dispute over e.g. IP, I would trust the } \\
\text { authorities to find justice* }\end{array}$ & 0.430 \\
\hline inst2 & $\begin{array}{l}\text { My firm could negotiate with any party because law and } \\
\text { the contracts would protect my knowledge and my } \\
\text { idea without any problem }\end{array}$ & 0.423 \\
\hline inst3 & $\begin{array}{l}\text { The legal system in Hungary guarantees the protection of } \\
\text { business ideas }\end{array}$ & 0.220 \\
\hline Locus & $\begin{array}{l}\text { Rotter's measurement design was used (scale from 0 to } \\
13, \text { higher values: external, lower values: internal } \\
\text { locus of control) }\end{array}$ & 6.631 \\
\hline riskperc1 & $\begin{array}{l}\text { I would know the main business development directions } \\
\text { and would not get lost with making the pet washing } \\
\text { kit a real product on the market, I would not perceive } \\
\text { substantial risk of realisation }\end{array}$ & 0.719 \\
\hline riskperc2 & $\begin{array}{l}\text { Even if the steps taken that far are logical, I am not } \\
\text { confident enough what the next steps would be } \\
\text { (reversed scale) }\end{array}$ & 0.018 \\
\hline riskperc3 & $\begin{array}{l}\text { Making the pet washing kit business a reality is risky, } \\
\text { most probably I would not be able to realise } \\
\text { substantial market success (reversed scale) }\end{array}$ & 0.507 \\
\hline
\end{tabular}

Note: * For all items except 'Locus': Likert scale from -3 to +3 ; the degree of agreement with the statement.

Table 4. Correlations and variances (in diagonal) of the measured variables

\begin{tabular}{|l|r|r|r|r|r|l|l|}
\hline & inst1 & inst2 & inst3 & Locus & riskperc1 & riskperc2 & riskperc3 \\
\hline inst1 & $2.628^{*}$ & & & & & & \\
\hline inst2 & $0.281^{*}$ & $3.175^{*}$ & & & & & \\
\hline inst3 & $0.295^{*}$ & $0.301^{*}$ & $2.733^{*}$ & & & & \\
\hline locus & $-0.140^{*}$ & $-0.136^{*}$ & $-0.171^{*}$ & $4.120^{*}$ & & & \\
\hline riskperc1 & $0.095^{*}$ & $0.116^{*}$ & $0.004^{*}$ & $-0.115^{*}$ & $2.090^{*}$ & & \\
\hline riskperc2 & $-0.007^{*}$ & $0.014^{*}$ & $0.022^{*}$ & $-0.137^{*}$ & $0.258^{*}$ & $2.476^{*}$ & \\
\hline riskperc3 & $0.010^{*}$ & $0.062^{*}$ & $0.046^{*}$ & $-0.089^{*}$ & $0.295^{*}$ & $0.396^{*}$ & $2.638^{*}$ \\
\hline
\end{tabular}

Note: *significant correlations at the $95 \%$ level.

In the measurement part of the model, the three observed variables of perceived institutional efficacy have approximately the same loading on the latent construct. For the other latent construct (risk perception of the case), the riskperc2 and riskperc3 items have somewhat higher loadings. 
Table 5. Parameter estimations and significance levels for the two models (SE in parentheses)

\begin{tabular}{|c|c|c|c|c|c|c|}
\hline & \multicolumn{2}{|c|}{ Model 1} & \multirow[b]{2}{*}{$P$} & \multicolumn{2}{|c|}{ Model 2} & \multirow[b]{2}{*}{$P$} \\
\hline & Unstandardised & Standardised & & Unstandardised & Standardised & \\
\hline \multicolumn{7}{|l|}{ Measurement model } \\
\hline $\begin{array}{r}\text { inst } \rightarrow \\
\text { inst1 } \\
\text { inst2 } \\
\text { inst3 }\end{array}$ & $\begin{array}{l}1.000(0.00) \\
1.121(0.26) \\
1.125(0.26)\end{array}$ & $\begin{array}{l}0.519(0.08) \\
0.529(0.08) \\
0.572(0.08)\end{array}$ & $\begin{array}{l}0.000 \\
0.000 \\
0.000\end{array}$ & $\begin{array}{l}1.000(0.00) \\
1.112(0.26) \\
1.126(0.27)\end{array}$ & $\begin{array}{l}0.520(0.08) \\
0.526(0.08) \\
0.574(0.08)\end{array}$ & $\begin{array}{l}0.000 \\
0.000 \\
0.000\end{array}$ \\
\hline $\begin{array}{r}\text { riskperc } \rightarrow \\
\text { riskperc1 } \\
\text { riskperc2 } \\
\text { riskperc3 }\end{array}$ & $\begin{array}{l}1.000(0.00) \\
1.435(0.32) \\
1.617(0.36)\end{array}$ & $\begin{array}{l}0.456(0.07) \\
0.600(0.08) \\
0.656(0.08)\end{array}$ & $\begin{array}{l}0.000 \\
0.000 \\
0.000\end{array}$ & $\begin{array}{l}1.000(0.00) \\
1.453(0.32) \\
1.617(0.35)\end{array}$ & $\begin{array}{l}0.453(0.07) \\
0.605(0.08) \\
0.653(0.08)\end{array}$ & $\begin{array}{l}0.000 \\
0.000 \\
0.000\end{array}$ \\
\hline \multicolumn{7}{|l|}{ Structural model } \\
\hline $\begin{array}{l}\text { inst } \rightarrow \text { locus } \\
\text { locus } \rightarrow \text { riskperc } \\
\text { inst } \rightarrow \text { riskperc }\end{array}$ & $\begin{array}{r}-0.691(0.22) \\
-0.055(0.03) \\
0.051(0.09)\end{array}$ & $\begin{array}{r}-0.285(0.08) \\
-0.170(0.08) \\
0.066(0.11)\end{array}$ & $\begin{array}{l}0.002 \\
0.057 \\
0.561\end{array}$ & $\begin{array}{l}-0.690(0.22) \\
-0.061(0.03)\end{array}$ & $\begin{array}{l}-0.286(0.08) \\
-0.190(0.08)\end{array}$ & $\begin{array}{l}0.002 \\
0.025\end{array}$ \\
\hline \multicolumn{7}{|l|}{ Variance of error terms } \\
\hline $\begin{array}{l}\text { e.inst1 } \\
\text { e.inst2 } \\
\text { e.inst3 } \\
\text { e.riskperc1 } \\
\text { e.riskperc2 } \\
\text { e.riskperc3 } \\
\text { e.locus } \\
\text { e.riskperc }\end{array}$ & $\begin{array}{l}1.91(0.23) \\
2.27(0.29) \\
1.83(0.26) \\
1.65(0.17) \\
1.57(0.23) \\
1.50(0.27) \\
3.77(0.35) \\
0.41(0.14)\end{array}$ & $\begin{array}{l}0.73(0.08) \\
0.72(0.08) \\
0.67(0.09) \\
0.79(0.06) \\
0.64(0.09) \\
0.57(0.10) \\
0.92(0.04) \\
0.96(0.03)\end{array}$ & & $\begin{array}{l}1.91(0.23) \\
2.28(0.29) \\
1.83(0.26) \\
1.65(0.17) \\
1.56(0.24) \\
1.51(0.27) \\
3.77(0.35) \\
0.41(0.14)\end{array}$ & $\begin{array}{l}0.73(0.08) \\
0.72(0.08) \\
0.67(0.09) \\
0.79(0.06) \\
0.63(0.09) \\
0.57(0.10) \\
0.92(0.04) \\
0.96(0.03)\end{array}$ & \\
\hline \multicolumn{7}{|l|}{ Fit indices } \\
\hline $\begin{array}{l}\text { Chi-square } \\
\text { Tucker-Lewis ind. } \\
\text { Comparative Fit } \\
\text { RMSEA } \\
\text { Degrees of freedom } \\
\text { R-square }\end{array}$ & $\begin{array}{l}7.61 \\
1.05 \\
1.00 \\
0.00 \\
\\
0.57\end{array}$ & 12 & 0.81 & $\begin{array}{l}7.96 \\
1.06 \\
1.00 \\
0.00 \\
\\
0.57\end{array}$ & 13 & 0.85 \\
\hline
\end{tabular}

In the structural part of the model, the parameter estimates are robust and have the expected signs. If institutional efficacy is perceived less efficient, it corresponds to more external and less internal locus of control, i.e. people feel less certain if they can control things. On the other hand, higher internal locus of control reduces the perceived level of risk of a concrete innovation case in its ideation phase (Figs. 5 and 6).

\subsection{Interpretation of results}

With the methodology developed, higher education student respondents were confronted with a specific innovation case: a new pet washing kit business idea. The transportation experience and the closest context were included by asking about involvement of a friend in the discussions. The created latent constructs (confidence and honesty of the situation construct and appropriate informedness of the friend) justified the existence of the transportation experience in a CFA. 


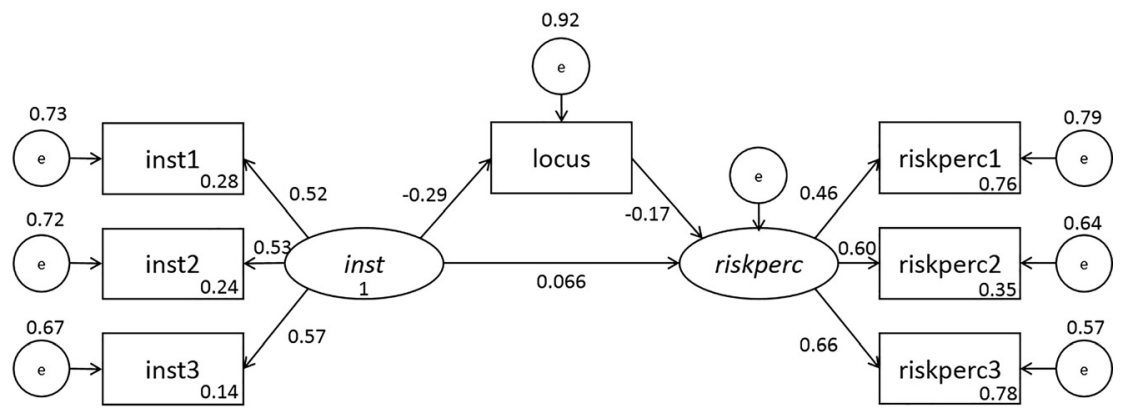

Fig. 5. Results for Model 1 (standardised estimates). Comparative Fit Index $=1.00$; root mean square error of approximation $=0.000 ;$ chi-square $=7.609 ; P$-value $($ chi-square $)=0.81 ;$ degrees of freedom $=12$

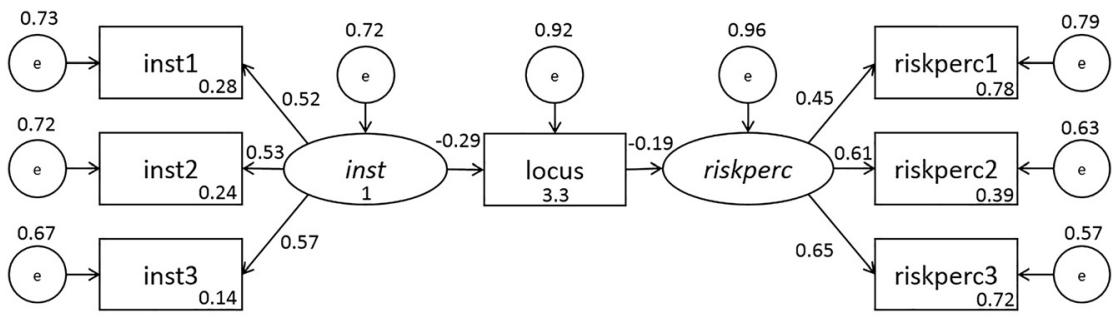

Fig. 6. Results for Model 2 (standardised estimates). Comparative Fit Index $=1.00$; root mean square error of approximation $=0.000$; chi-square $=7.957 ; P$-value $($ chi-square $)=0.84$; degrees of freedom $=13$

As regards the ideation phase of entrepreneurial innovation activities, a Structural Equation Model showed relevance of the theoretical constructs that aimed at connecting micro(or individual) and macro-level variables. These variables have been selected by combining the different entrepreneurship research approaches. For the structural model, two latent variables (risk perception of the specific case and perceived institutional efficacy) were used and the locus of control variable was directly observed. All coefficients had the expected signs and according to the fit indices, the SEM structure is robust.

The results of the structural models confirm that as long as entrepreneurial innovation success is determined by risk perception during the ideation phase, it will be shaped by macro-level factors (of which perceived institutional efficacy was measured) as these have an influence on risk perception through locus of control. If we accept these results, we could argue that even entrepreneurship students with high risk perception and strong internal locus of control could lose their interest in forwarding their idea when the surrounding environment is not favouring the entrepreneurial way. Certainly, the pet washing kit is a made-up case and we cannot be sure that in the real world entrepreneurial innovation situations these mechanisms work the same way. However, during the questionnaire survey there was the transportation experience effect and so there is some likelihood that entrepreneurial thinking is similar in similar entrepreneurial contexts. 


\section{CONCLUSIONS}

Devising a testable theory-based survey measurement tool to understand underlying factors that lead to starting an innovative business poses certain challenges. Experience is rare and there have been few attempts to link internal and external variables to the formation stage of new ventures. Martinez et al. (2018) is an exception, aiming at a comprehensive understanding about the perceived feasibility of starting a new business in incubators. In their article, two feasibility antecedents are contemplated: self-efficacy (internal component) and the facilitating conditions or contextual factors (external component). Our approach makes a new contribution by offering empirical insights into the usefulness of a story-based questionnaire and finding causal relationships under more generic circumstances.

In the early stage of innovation, the judgement or the series of judgements on the (perceived) opportunity seems to be crucial as entrepreneurs will dedicate the necessary efforts and resources to make an innovative idea reality if and only if their judgement is positive. ${ }^{9} \mathrm{We}$ dedicated the paper to how this judgement is shaped and how we can approach the problem of individual and higher-level factors. By having the narrative under control, the analysis of multiple level impacts became possible using a questionnaire survey.

Innovation studies that use multilevel approaches typically incorporate variables that originate from secondary sources (e.g. official statistics or measurements published by other organisations). When questionnaire-based primary research is conducted, innovation and innovative behaviour often remains a general abstraction despite the theoretical advancement that assigns the key importance to the narrative perspective in the case of entrepreneurial innovation (Garud et al. 2014). Our approach is an attempt to overcome some of the limitations of conventional survey methodologies, which are not so well-suited to the study of the ideation phase of entrepreneurial innovation, i.e. when the 'serious decisions' are made and when the perception of the state of many contexts are involved. Use of the case-based narrative was justified on the grounds of better structuring opportunity (Davidsson 2015) and the potential transportation experience (Glaser et al. 2012), which was expected to deliver better quality responses. The research presented showed the importance of the interplay of institutional factors, individual personality characteristics and opportunity evaluation, before entrepreneurial decisions are made (the empirical testing involved perceived efficacy of institutions, locus of control and risk perception). It is now more clearly understood how individual entrepreneurs approach the start of their innovation-based business, upon which personality and environmental factors both have significant impact.

A new generation of story-based measurements may better structure our understanding of the crucial decisions in, and right after, the ideation phase of the entrepreneurial innovation process. This conclusion is in line with the importance of pitching ideas and idea selection that are often story-based. Investors, innovation managers and decision-makers generally buy in teams (Franke et al. 2008) and usually get hooked on stories. Zacharakis - Shepherd (2001) found that overconfident VCs may not fully consider all relevant information, nor search for additional information to improve their decision.

Story-based measurement may be used in pre-selection of university students for elective entrepreneurship classes and focus the training on those who have a higher potential of success.

\footnotetext{
${ }^{9} \mathrm{We}$ acknowledge that there are cases, when not opportunities drive entrepreneurship.
} 
This is in line with the proposal of Lüthje - Franke (2003), who, indeed suggested such selection to focus on students with higher entrepreneurial potential.

Nevertheless, the paper has several limitations that could be tackled in future investigations. The control for the narrative looks easier for examining the ideation phase, as in the later stages of the entrepreneurial innovation process the highly case-specific contexts may narrow down the space for generalisation. The student sample used may contrast results of measuring 'real-life' entrepreneurial innovation. Finally, a wider literature survey is needed to craft more detailed structures for the interrelated multilevel factors. For instance, according to Simon et al. (2000), three cognitive biases, which are characteristic of entrepreneurs, reduce the perceptions of risk: overconfidence, the illusion of control and the belief in the law of small numbers (when an individual uses a small number of information inputs to draw firm conclusions). Overconfidence has also been noted by Robinson - Marino (2015). One way to future research is mapping out these interrelations, involving also more fine-tuned narrative methodologies.

\section{ACKNOWLEDGEMENT}

This paper was supported by the János Bolyai Research Scholarship of the Hungarian Academy of Sciences (Grant number GINOP-2.3.4-15-2016-00003) and the project titled "Centre for cooperation between higher education and the industries at Széchenyi István University (FIEK)".

\section{REFERENCES}

Ács, Z. J. - Autio, E. - Szerb, L. (2015): National Systems of Entrepreneurship: Measurement Issues and Policy Implications. Research Policy, 43(1): 476-494.

Ajzen, I. (1991): The Theory of Planned Behavior, Organizational Behavior and Human Decision Processes. Science Direct, 50(2): 179-211.

Alsos, G. A. - Hytti, U. - Ljunggren, E. (eds) (2016): Research Handbook on Gender and Innovation. Edward Elgar Publishing.

Bergmann, H. - Hundt, C. - Sternberg, R. (2016): What Makes Student Entrepreneurs? On the Relevance (and Irrelevance) of the University and the Regional Context for Student Start-ups. Small Business Economics, 47(1): 53-76.

Bessant, J. - Tidd, J. (2011): Innovation and Entrepreneurship. Second ed., John Wiley \& Sons, Inc.

Buli, B. M.- Yesuf, W. M. (2015): Determinants of Entrepreneurial Intentions: Technical-Vocational Education and Training Students in Ethiopia. Education+ Training, 57(8/9): 891-907.

Bygrave, W. - Zacharakis, A. (2011): Entrepreneurship. Second ed., John Wiley \& Sons, Inc.

Camacho-Miñano, M. D. M. - del Campo, C. (2017): The Role of Creativity in Entrepreneurship: An Empirical Study on Business Undergraduates. Education+ Training, 59(7/8): 672-688.

Cooper, R. (1994): Third-Generation New Product Processes. Journal of Product Innovation Management, 11(1): 3-14.

Davidsson, P. (2015): Entrepreneurial Opportunities and the Entrepreneurship Nexus: A Re-Conceptualization. Journal of Business Venturing, 30(5): 674-695. 
Drucker, P. F. (1985): Innovation and Entrepreneurship. Practice and Principles. Harper and Row.

Dunphy, S. M. - Herbig, P. R. - Howes, M. E. (1996): The Innovation Funnel. Technological Forecasting and Social Change, 53(3): 279-292.

Fagerberg, J. (2005): Innovation: A Guide to the Literature. In: Fagerberg, J. - Mowery, D. C.- Nelson, R. R. (eds): The Oxford Handbook of Innovation. Oxford University Press, pp. 1-27. https://doi.org/10.1093/ oxfordhb/9780199286805.003.0001.

Farhangmehr, M. - Gonçalves, P.- Sarmento, M. (2016): Predicting Entrepreneurial Motivation among University Students: The Role of Entrepreneurship Education. Education+ Training, 58(7/8): 861-881.

Fortunato, M. W. - Alter, T. R. (2011): The Individual-Institutional-Opportunity Nexus: An Integrated Framework for Analyzing Entrepreneurship Development. Entrepreneurship Research Journal, 1(1): $1-34$.

Franke, N. - Gruber, M. - Harhoff, D. - Henkel, J. (2008): Venture Capitalists' Evaluations of Start-up Teams: Trade-Offs, Knock-Out Criteria, and the Impact of VC Experience. Entrepreneurship Theory and Praxis, 32(3): 459-483.

Garud, R. - Gehman, J. - Giuliani, A. P. (2014): Contextualizing Entrepreneurial Innovation: A Narrative Perspective. Research Policy, 43(7): 1177-1188.

Gassman, O. - Schweitzer, F. (2012): Managing the Unmanageable: The Fuzzy Front End of Innovation. In: Gassman, O. - Schweitzer, F. (eds): Management of The Fuzzy Front End of Innovation. Springer, pp. 3-14.

Gird, A.- Bagraim, J. J. (2008): The Theory of Planned Behaviour as Predictor of Entrepreneurial Intent Amongst Final-Year University Students. South African Journal of Psychology, 38(4): 711-724.

Glaser, M. - Garsoffky, B. - Schwan, S. (2012): What Do We Learn from Docutainment? Processing Hybrid Television Documentaries. Learning and Instruction, 22(1): 37-46.

Gubik, A. - Farkas, Sz. - Kása, R. (2018): A tervezett magatartás elméletének alkalmazása a vállalkozói hajlandóság alakulásának magyarázatára (Applying the Theory of Planned Behaviour to Explaining the Evolution of Entrepreneurship). Közgazdasági Szemle, 65(1): 74-101.

Gurel, E. - Altinay, L.- Daniele, R. (2010): Tourism Students' Entrepreneurial Intentions. Annals of Tourism Research, 37(3): 646-669.

Hatak, I. - Harms, R. - Fink, M. (2015): Age, Job Identification, and Entrepreneurial Intention. Journal of Managerial Psychology, 30(1): 38-53.

Houser, C. (2014): Why the University Is the Ideal Start-up Platform. http://www.wired.com/2014/02/ university-ideal-startup-platform/, accessed 10 January 2018.

Hueske, A. K. - Endrikat, J. - Guenther, E. (2015): External Environment, the Innovating Organization, and Its Individuals: A Multilevel Model for Identifying Innovation Barriers Accounting for Social Uncertainties. Journal of Engineering and Technology Management, 35: 45-70.

Jalonen, H. (2012): The Uncertainty of Innovation: A Systematic Review of the Literature. Journal of Management Research, 4(1): 1-47.

Judge, T. A. - Erez, A. - Bono, J. E. - Thoresen, C. J. (2002): Are Measures of Self-Esteem, Neuroticism, Locus of Control, and Generalized Self-Efficacy Indicators of a Common Core Construct? Journal of Personality and Social Psychology, 83(3): 693-710.

Kautonen, T. - Van Gelderen, M. - Tornikoski, E. T. (2013): Predicting Entrepreneurial Behaviour: A Test of the Theory of Planned Behaviour. Applied Economics, 45(6): 697-707.

Krueger, Jr, N. F. - Reilly, M. D. - Carsrud, A. L. (2000): Competing Models of Entrepreneurial Intentions. Journal of Business Venturing, 15(5-6): 411-432.

Kuckertz, A. - Wagner, M. (2010): The Influence of Sustainability Orientation on Entrepreneurial Intentions - Investigating the Role of Business Experience. Journal of Business Venturing, 25(5): 524-539. 
Lüthje, C. - Franke, N. (2003): The 'Making' of an Entrepreneur: Testing a Model of Entrepreneurial Intent among Engineering Students at MIT. R\&D Management, 33(2): 135-147.

Martínez, K. R. G. - Fernández-Laviada, A. - Crespo, Á. H. (2018): Influence of Business Incubators Performance on Entrepreneurial Intentions and Its Antecedents during the Pre-incubation Stage. Entrepreneurship Research Journal, 8(2): 1-15.

Meyer, A. D. - Goes, J. B. (1988): Organizational Assimilation of Innovations: A Multilevel Contextual Analysis. Academy of Management Journal, 31(4): 897-923.

Mishra, C. S. - Zachary, R. K. (2015): The Theory of Entrepreneurship. Entrepreneurship Research Journal, 5(4): 251-268.

Mueller, S. L. - Thomas, A. S. (2001): Culture and Entrepreneurial Potential: A Nine Country Study of Locus of Control and Innovativeness. Journal of Business Venturing, 16(1): 51-75.

Obschonka, M. - Stuetzer, M. (2017): Integrating Psychological Approaches to Entrepreneurship: The Entrepreneurial Personality System (EPS). Small Business Economics, 49(1): 203-231.

Pavitt, K. (2005): Innovation Process. In: Fagerberg, J. - Mowery, D. C. (eds): The Oxford Handbook of Innovation. Oxford University Press, pp. 86-114.

Robinson, A. T. - Marino, L. D. (2015): Overconfidence and Risk Perceptions: Do They Really Matter for Venture Creation Decisions? International Entrepreneurship and Management Journal, 11(1): 149-168.

Schumpeter, J. A. (1934): The Theory of Economic Development: An Inquiry into Profits, Capital, Credits, Interest, and the Business Cycle. Piscataway: Transaction Publishers.

Shepherd, D. A. - Mcmullen, J. S. - Jennings, P. D. (2007): The Formation of Opportunity Beliefs: Overcoming Ignorance and Reducing Doubt. Strategic Entrepreneurship Journal, 1(1-2): 75-95.

Shkedi, A. (2004): Narrative Survey: A Methodology for Studying Multiple Populations. Narrative Inquiry, 14(1): 87-111.

Simon, M. - Houghton, S. M. - Aquino, K. (2000): Cognitive Biases, Risk Perception, and Venture Formation: How Individuals Decide to Start Companies. Journal of Business Venturing, 15(2): 113-134.

Tidd, J. - Bessant, J. (2013): Managing Innovation: Integrating Technological, Market and Organizational Change. Fifth ed., JohnWiley \& Sons, Inc.

Vandenbosch, B. - Saatcioglu, A. - Fay, S. (2006): Idea Management: A Systemic View. Journal of Management Studies, 43(2): 259-288.

Wood, M. S. - Mckelvie, A. - Haynie, J. M. (2014): Making it Personal: Opportunity Individuation and the Shaping of Opportunity Beliefs. Journal of Business Venturing, 29(2): 252-272.

Woolley, J. L. (2011): Studying the Emergence of New Organizations: Entrepreneurship Research Design. Entrepreneurship Research Journal, 1(1): 1-26.

Zacharakis, A. L. - Speherd, D. (2001): The Nature of Information and Overconfidence on Venture Capitalists' Decision Making. Journal of Business Venturing, 16(4): 311-332.

Zhang, P. - Wang, D. D. - Owen, C. L. (2015): A Study of Entrepreneurial Intention of University Students. Entrepreneurship Research Journal, 5(1): 61-82.

Open Access. This is an open-access article distributed under the terms of the Creative Commons Attribution 4.0 International License (https://creativecommons.org/licenses/by/4.0/), which permits unrestricted use, distribution, and reproduction in any medium, provided the original author and source are credited, a link to the CC License is provided, and changes - if any - are indicated. (SID_1) 